\title{
Academia Should Embrace Open Access Scholarly Publishing
}

\author{
Hubert D. Glover \\ Department of Accounting, LeBow College of Business, Drexel University, Philadelphia, USA \\ Email: hdg26@drexel.edu
}

Received July 15, 2013; revised August 21, 2013; accepted September 1, 2013

Copyright (c) 2013 Hubert D. Glover. This is an open access article distributed under the Creative Commons Attribution License, which permits unrestricted use, distribution, and reproduction in any medium, provided the original work is properly cited.

Dear Editor,

During the early part of the $21^{\text {st }}$ Century, AT\&T and Verizon noted that revenue from traditional residence based land lines had been surpassed by wireless revenues. Likewise, Amazon noted just a few years ago a similar milestone when e-books surpassed paper books' revenues. PC manufacturers such as HP are seeking declines in sales while mobile phone manufactures such as Samsung experience significant sales increase as more consumers globally access the internet via mobile connections. Similarly more and more of the millions of students enrolled around the world today take courses in some form of online education or Massive Online Open Courses (MOOCs).

When I was working on my doctorate at Texas A\&M University I represented my department at the annual accounting doctoral student symposium hosted by Deloitte in 1991. During that symposium the late Alvin Arens noted that the emergence of information technology was closing the gap between larger and smaller academic institutions. Arens notes that the inherent resource difference is mitigated by technology such as electronic databases with journal articles or financial information. Thereby, allowing faculty and doctoral students to conduct similar lines of inquiry despite the size of the institution.

My co-author in a recently published book "Giraffes of Technology: The Making of the Twenty-First Leader" notes that technology provides a democratization of information. In other words from the most rural and lower socio economic level to the most developed and affluent groups, information is equally available.

Finally, I recall submitting a proposal regarding the consolidation of university resources into one central electronic database and the elimination of paper subscriptions in 1994 at my first academic institution. The proposal was soundly rejected as it was premature. However, today, many colleges have reorganized their libraries to be part of the their information resources group, eliminated or greatly reduced paper based subscriptions and replaced with enterprise or bulk electronic subscriptions and access to mainstream and proprietary databases are a priority if not the norm.

The economy has become clearly global as the recession that began in 2007 had an effect throughout the world as markets due to technology and trade are interconnected as never before. Just look at the US stock markets that ebb and flow on the economic reports from China to Greece. Today more than 100 companies have adopted International Financial Reporting Standards (IFRS) and many more will adopt in the future. The former G2 is now G20 and growing.

Our scholarly activities should mirror the global market trends. I have sat on the boards of the American Institute of Certified Public Accountants (AICPA) and Institute of Management Accountants (IMA) who now have significant global strategies. I am also serving on the finance committee for the American Accounting Association (AAA) which has more than a third of its membership is international.

Thus, I am excited about the latest trend in academic publishing which is open access. Some of our leading and prolific business scholars are now paying for open access to their articles. Despite their publication in tier one journal, I asked one of these leading scholars in accounting why he elected to pay thousands for open access and he noted "our goal is to advance the profession by contributing to the body of knowledge... hence it is essential that as many as possible access this contribution to generate an organic and dynamic response....”

The launching of the Open Journal of Accounting is an innovative step to facilitating the requisite exchange of ideas, contributions to the body of knowledge and the access to best practices in research, pedagogy and other key issues facing our profession.

Leading scholars are willing to expend financial re- 
sources when they have no incentive from a promotion and tenure perspective to ensure access to their information. We should formalize their pioneering steps to share their research by offering a medium for scholars around the globe to contribute to advancing the profession.

\section{Conclusion}

The business and academic landscape will continue to change and the underlying message access to information must be free or a reasonable cost and the ability to access must be efficient and effective. 